\title{
China's COVID-19 Vaccination Strategy and Its Impact on the Global Pandemic
}

\author{
Zhigang Meng ${ }^{1,2}$ \\ Shoujin Shan' \\ Ruilian Zhang $\mathbb{D}^{3}$ \\ 'School of Marxism, Hohai University, \\ Nanjing, 21 I I00, People's Republic of \\ China; ${ }^{2}$ North China University of Water \\ Resources and Electric Power, Henan, \\ Zhengzhou, 450046, People's Republic of \\ China; ${ }^{3}$ Sustainable Minerals Institute, \\ The University of Queensland, Brisbane, \\ Australia
}

\begin{abstract}
Public health crises are challenging for governments and health systems. Vaccines are a key solution to viruses, and immunization has always played a critical role during public health crises in the past century. In the context of coronavirus disease 2019 (COVID19), we explore China's vaccination strategies and challenges. Accordingly, we identify the causes of the high vaccination rate in China, including technical and nontechnical factors. Considering the impact of China's high vaccination rate on the global pandemic, we argue that it has strengthened China's opportunities and capabilities to participate in global development, enhanced the equity of vaccines and given the world community more choices.
\end{abstract}

Keywords: public health crisis, vaccines, equity, COVID-19

\section{Introduction}

Although multiple measures have been taken to slow the spread of SARS-CoV-2, the causative agent of coronavirus disease (COVID-19), variants of the RNA virus have emerged in an endless stream (Alpha, Beta, Gamma, Delta, Lambda) since early 2020. According to World Health Organization (WHO) data, as of September 2, 2021, the cumulative number of confirmed cases worldwide has exceeded 218 million, the death toll has exceeded 4.53 million, and the number of vaccinations worldwide has reached 5.29 billion. $^{1}$ On August 31, the report showed that there were $193,141,91$, and 170 countries and regions with 4 variants of SARS-CoV-2, Alpha, Beta, Gamma, and Delta, respectively. ${ }^{2,3}$

Around the world, different countries' development histories, sociopolitical and economic systems, and cultural backgrounds have determined their different approaches to governance. ${ }^{4}$ In the face of the global outbreak of COVID-19, the response strategies adopted by countries have varied widely. The governments of some countries or regions, represented by China, have adopted active measures to fight the pandemic for all people, regardless of the cost of saving lives. Some Western governments, such as those of the United Kingdom and Norway, have advocated a passive response by promoting herd immunity, which means that sixty percent of adults may have to be vaccinated to achieve collective immunity. ${ }^{5}$ However, due to the rapid spread of the Delta strain, its easier adaptability to the human body, fast replication, and high viral load, as well as major loopholes in the pandemic precautions at Nanjing Lukou Airport in July 2021, the pandemic broke out again in some cities in China. Although the virus had been effectively controlled in September, the new outbreak and the overall milder symptoms of confirmed cases once again strongly prove the importance of
Correspondence: Ruilian Zhang Sustainable Minerals Institute, The University of Queensland, Brisbane, 4072, Australia

Tel +6I48II20982

Email ruilian.zhang@uq.edu.au 
COVID-19 vaccines. Therefore, China's vaccination strategy and its impact on the global pandemic deserve further in-depth study.

Four sections follow this introduction. Section 2 introduces China's vaccination strategies and challenges. Section 3 states the causes of the high vaccination rate in China. Section 4 explains the impact of China's high vaccination rate on the global pandemic. Section 5 concludes the paper.

\section{China's Vaccination Strategies and Challenges}

\section{Achievements of Vaccination}

Quoting an Associated Press report, "China is doing something that almost no country in the world can do in COVID-19 vaccination." Indeed, China's current average vaccination rate has exceeded 19 million doses per day, while the US vaccination rate is only 3.4 million doses per day. According to data released by the National Health Commission, it took 25 days to go from 100 million doses to more than 200 million doses in China. From 200 million to over 300 million doses, it took 16 days. From 300 million doses to over 400 million doses, it took 9 days. From 600 million doses to 700 million doses, it took only 5 days. ${ }^{6}$ The total number of people who have had a first dose of the vaccine has reached 1.095 billion, covering $77.6 \%$ of the country's total population, and 969.72 million people had been fully vaccinated as of September 6, 2021. To date, China's high-risk areas have been cleared, and the number of medium-risk areas has dropped to three. On September 6, China reported a total of 2.113 billion doses of COVID-19 vaccines had been distributed across the country. ${ }^{1}$ Since the outbreak, China has laid out five technical pathways to promote the development of COVID-19 vaccines: inactivated vaccines, adenovirus vector vaccines, recombinant protein vaccines, attenuated influenza virus vector vaccines and nucleic acid vaccines. The main purpose is to ensure successful inoculation of the populations. To date, all five types of vaccines have completed full clinical trials.

\section{Promoting Vaccination and Overcoming Problems}

During the vaccination process, various provinces have explored many useful experiences and practices. Some cities have set up temporary vaccination sites based on routine vaccination clinics. Some provinces have explored setting up temporary vaccination sites in large sports venues. ${ }^{7}$ Some provinces have also opened an online appointment service. In some cities, the focus of pandemic prevention and control has been combined to ensure that key populations in port cities are given priority for vaccination. In some cities, to ensure the standard and safety of the vaccination process, the National Health Commission has also sent a supervisory team to guide local authorities in arranging all aspects of vaccination in accordance with government requirements. ${ }^{8,9}$

The vaccination rate in Chinese cities is relatively high, the mobilization process is relatively smooth, and citizens have a high health risk awareness. However, in rural areas, vaccination and mobilization are still underway, and the vaccination rate has been lagging. However, rural areas are also trying to take measures to speed up the process. For example, some areas in Hunan Province shuttle villagers for free to get their vaccinations in more urban areas. The hours of vaccination locations have been extended to 10 pm for the convenience of the public. ${ }^{7}$ Guangdong Province arranges for health care professionals to drive into rural areas and communities to administer vaccinations. To ensure that residents in the remote mountainous areas of the Tibet Autonomous Region have a better understanding of the disease and access to vaccines, some officials have spared no effort in going door to door to educate the population. Vaccine promoters in Zuogong County in Tibet travel more than 400 kilometres to promote vaccines every day, and more than 30,000 out of approximately 50,000 residents have received their first shot. ${ }^{10}$

Is vaccination voluntary or involuntary? The National Health Commission has repeatedly emphasized that China encourages voluntary vaccination against COVID-19 and strives to ensure that all those eligible for vaccination have access to the vaccine. ${ }^{7}$ Vaccination follows the basic principles of "informed, agreed, and voluntary". However, in the mobilization and vaccination process, there is still some individual discordant phenomena. ${ }^{2,4}$ As China speeds up vaccination efforts, some local governments have adopted extreme one-size-fits-all policies. For example, under the pressure of realizing herd immunity and reducing the outbreak of the pandemic, some local governments have interpreted the push for vaccination as a "rigid goal" that must be met. For this reason, many villages and towns have formulated strict key performance indicators (KPIs). To achieve the KPIs, grocery awards (rice, flour, oil) and cash rewards of 200 to 300 yuan are given as 
incentives to be vaccinated. However, such measures have not been enough. According to media reports, at least two districts in Chongqing have issued notices stating that if people over age 18 without contraindications refuse to be vaccinated for no reason, they can be registered in the social dishonesty system. ${ }^{6}$ It is not easy for local governments to fulfil their missions while honouring individuals' right to voluntarily submit to vaccination. Overall, deviating from the central policy is the behaviour of individual local governments, which does not mean that the country has changed its policies.

Are the policies consistent or inconsistent? The policies and standards surrounding the vaccination process are incomplete and not yet standardized. Elderly individuals generally have more serious chronic diseases, mainly hypertension, heart disease, diabetes, and tumours. ${ }^{11}$ However, before vaccination began, no contraindications were mentioned, elderly individuals' guardians were not contacted, and there was insufficient communication during the vaccination process. Although the COVID-19 Vaccination Technical Guidelines (First Edition) were issued by the National Health Commission, the contraindications for vaccination did not directly mention the common chronic diseases of the elderly, such as high blood pressure, heart disease, diabetes, and tumors, posing extra risk to that specific population. Further, each region had its own rules and enforcement. For example, an elderly individual with high blood pressure may be treated differently in different locations.

\section{The Causes of the High Vaccination Rate in China

Technical Factors

Multiple vaccines are being developed simultaneously. In 2020, COVID-19 swept the world. To maximize the success rate of COVID-19 vaccine research and development, China laid out five technical routes to successful vaccines: inactivated vaccines, recombinant protein vaccines, adenovirus vector vaccines, attenuated influenza virus vector vaccines and nucleic acid vaccines. ${ }^{10}$ The vaccine technologies that have been approved for marketing and used in China are mainly inactivated vaccines, recombinant protein vaccines, and adenovirus vector vaccines. Among them, inactivated vaccines require 2 injections (vaccine efficacy $72.8 \%$ ); recombinant protein vaccines require 3 injections (vaccine efficacy 83.5\%); and adenovirus vector vaccines require only 1 injection (vaccine efficacy $74.8 \%$ ).
By March 2021, five COVID-19 vaccines had been approved for marketing in China.

Vaccine production plants operate 24 hours a day. To maximize the production and supply of vaccines and ensure the needs of vaccination work are met, the Ministry of Industry and Information Technology, together with relevant departments and localities, dispatched service guarantee teams to relevant enterprises. Each team works with the companies to formulate plans to increase production and capacity, requiring companies to reverse production schedules, optimise scientific production scheduling, and efficiently allocate production factors, such as personnel, equipment, and consumables, in an effort to ensure the stability of production. In addition, with the expansion of manufacturing capacity, domestic vaccine production is gradually growing. According to the current production arrangements, annual vaccine production can fully meet the vaccination needs of people across the country.

Vaccinations are free for all people. After solving the vaccine approval process and production capacity, the pricing of the COVID-19 vaccine has always been the focus of the Chinese people. In January and September 2021, Li Tao, deputy director of the National Medical Security Administration, stated that China will implement the COVID-19 vaccination free of charge in line with the principle of people and life first. The cost of vaccination will be borne by the medical insurance fund and finance together, and residents will not bear the cost. Before this, the winning bidders of Beijing Sinovac Research \& Development Co., Ltd. and Beijing Institute of Biological Products Co., Ltd. planned to charge for the vaccine. In December 2020, according to the Jiangsu Provincial Pharmaceuticals (Medical Consumables) Sunshine Procurement and Comprehensive Supervision Platform, the "Notice of the Provincial Public Resources Trading Centre on Announcement of the Procurement Results of COVID-19 Vaccines" was issued and pointed out that the bid price had been 200 yuan/dose. This is a huge fiscal expenditure that could not be ignored by the government.

\section{Non-Technical Factors}

Pandemic prevention and control remain critical. From the perspective of the international environment, the COVID19 pandemic continues, new outbreaks occur, and the death toll is rising. As global travel resumed, imported cases of the virus and its variations from overseas challenged China's ability to control and prevent spread of the 
disease. If vaccination is not accelerated and promoted nationwide, the results of domestic pandemic stabilization and control will be undermined. From the perspective of the domestic environment, although China's prevention and control of domestic outbreaks has been very successful, the imported cases pose an additional threat to population health as well as the health of the economy. China cannot be closed for long without disrupting supply chains worldwide and hindering China's participation in globalization. Therefore, to minimize these, speeding up the vaccination of all people and forming an immune barrier are urgent. The pandemic in the international community is severe, and the continuous emergence of variant viruses is a concern for all, including China.

Local governments felt the political pressure to vaccinate their citizens. After the successful research and development of the COVID-19 vaccine, the Communist Party Central Committee put out a unified call to ensure that regions supported vaccination. Although the central government emphasized that vaccination should be voluntary, the local government officials still felt huge political pressure. If there were cases in the area where the local governments were located or an outbreak caused a wider spread, the responsible leaders risked dismissal. To prevent this, local governments mobilized all resources, concentrated all forces, and tried all imaginable methods to actively carry out vaccination work. Encouraged by their local governments, especially driven by the demonstration of specific groups such as medical staff, PLA soldiers, and public officials, the general public actively cooperated in vaccination work and jointly created the "Chinese speed" of vaccination. At the same time, all kinds of publicity for vaccines were in place - such as posters, videos, all-media matrix linkages, online and offline multiform and multichannel promotions - transmitting vaccination information to every corner of society. Vaccination organizations were in place, and grassroots party members and cadres travelled to communities and villages to organize vaccination work, optimize vaccination procedures, and effectively improve vaccination coverage.

The Chinese people trust in the government and the effectiveness of China's vaccines. The solid foundation laid by China's market reform in recent decades has improved citizens' living standards. People are full of hope in life and believe in the ability of the government to govern. Under the guidance of the Chinese government, China's COVID-19 vaccine production runs 24 hours a day, and many vaccines produced in China have been approved by the World Health Organization and put into emergency use. This has increased the Chinese people's trust in vaccinations.

Chinese personal health awareness is improving. In recent years, the state has issued numerous policies and regulations to protect the health of the people and to encourage the development of the health industry. On October 25, 2016, the "Healthy China 2030" Planning Outline was released, which is the first medium- and longterm strategic plan in the health field proposed at the national level since the founding of the People's Republic of China. In July 2019, the State Council formally issued the "Opinions of the State Council on the Implementation of the Healthy China Action" and promoted the implementation of "Healthy China" as an important national strategy. On June 1, 2020, the "Law of the People's Republic of China on Basic Medical Care and Health Promotion" came into effect. For the first time, it was clearly stated at the legal level that health is a basic human right and its fairness was guaranteed. Encouraged by policies, China's health industry has scaled up. With the introduction of relevant national policies and regulations and the promotion of industrial clusters, the health awareness of the Chinese people is increasing daily, which is mainly reflected in the increasing demand for products such as medicines, health care, nutrition, sports and fitness. This has contributed to the country's overall higher vaccination rate.

\section{Discussion and Implications: The Impact of China's Vaccination Strategy on the Global Pandemic Strengthening China's Opportunities and Capabilities to Participate in Global Development}

By the end of August 2021, 5.29 billion doses of vaccine had been given globally, 67.22 doses per 100 people. ${ }^{12-18}$ China has received a total of 2.06 billion doses, 142.84 doses per 100 people. ${ }^{1}$ The global distribution of the COVID-19 vaccine is not balanced. In his speech at a press briefing on August 4, 2021, World Health Organization Director-General Tedros Adhanom said that high-income countries are now receiving nearly 100 doses of vaccine for every 100 people. At the same time, due to insufficient supplies, low-income countries are only receiving 1.5 doses of vaccine for every 100 people. ${ }^{19}$ 
Therefore, the WHO called for a suspension of booster injections at least until the end of September so that at least $10 \%$ of the population in each country can be vaccinated, and $40 \%$ of the population will be vaccinated by the end of December. Although China is not a developed country, due to the efficiency of the government, the current supply of COVID-19 vaccine is abundant. The vaccination coverage rate is advanced, with a vaccination rate of 142.84 doses per 100 people; 969.72 million people have completed two doses of vaccine, for a percentage of $62.7 \%$ of the total population. ${ }^{1,20}$

The COVID-19 pandemic has given domestic vaccines the best opportunity to go global. First, the domestic pandemic is well controlled. Therefore, Zhifei Biological Products Co., Ltd. and other domestic companies developing COVID-19 vaccines must go abroad to conduct Phase III clinical trials, objectively accumulating experience in organizing overseas clinical trials among different populations, and at the same time gaining the trust of trial countries. Except for China, the United States, the United Kingdom, and Russia, most countries do not have the ability to develop and produce COVID-19 vaccines. Further, the production capacity of developed countries is seriously insufficient, which objectively creates conditions for Chinese vaccine companies to export. China has already made its own contribution to the prevention and control of the pandemic and has enhanced the country's national image and world influence. Recently, the Delta strain of the virus has invaded more than 90 countries or regions around the world, bringing new threats to a world that is already shrouded in the haze of the pandemic. Speeding up vaccination and enabling herd immunity to run ahead of the spread of viral variations has become the first choice for multinational strategies.

\section{Enhancing the Equity of Vaccines and Offering More Choices to the Global Community}

The current imbalance and inequality of vaccination is evident worldwide. Individual countries have even stockpiled several times the number of COVID-19 vaccines needed to treat their own populations, resulting in no vaccines available in some developing countries. ${ }^{21}$ To solve the problem of vaccine production capacity and distribution, China has repeatedly put forward China's propositions at international conferences. In May 2020, at the 73rd World Health Assembly, China solemnly promised that after the research and development of China's COVID-19 vaccine is completed and put into use, it will become a global public product available and affordable in developing countries. At the Global Health Summit in May this year, China firmly called for the abandonment of "vaccine nationalism" and reiterated the resolution of vaccine production and distribution issues to increase accessibility and affordability in developing countries. At present, China has provided more than 350 million doses of vaccine to the international community with limited production capacity and despite a huge domestic demand. ${ }^{16}$ This includes providing vaccine assistance to more than 80 developing countries with an urgent need and exporting vaccines to more than 40 countries. China has also joined the WHO-led COVID-19 Vaccines Global Access (COVAX), promising to provide the first batch of 10 million doses of vaccine. On June 1, 2021, the first batch of COVAX vaccines supplied by Sinopharm Co., Ltd. was produced, and several updates were realized: English-language packaging was used, and the vaccine bottle monitor (the label on the vaccine bottle can monitor the surrounding environmental temperature changes) was activated; the vaccine package was specially printed with a QR code for international supervision; and the vaccine instructions were supplemented and improved. On the same day, Beijing Sinovac Biotechnology Co., Ltd. developed the COVID-19 inactivated vaccine "Sinovac COVID-19 vaccine", which formally passed the WHO emergency use certification. Together with the previously certified Sinopharm China Biological Vaccine, the two Chinese COVID-19 vaccines are aimed at alleviating the unfair distribution of global vaccines. To make a greater effort to remedy the tight supply of vaccines, Chinese vaccine companies are speeding up joint research and product authorization with capable countries. At the end of March 2021, the COVID-19 vaccine stock solutionfilling production workshop jointly built by Sinopharm and UAE G42 Group officially sub-packaged the COVID-19 inactivated vaccine. In terms of the effectiveness evaluation and authorized production of the vaccine, Sinovac has also carried out a fruitful collaboration with its Brazilian partners. For example, a phase III clinical trial was carried out among 12,000 medical staff to prove the safety and effectiveness of the vaccine.

At present, three enterprises in China have carried out joint production with eight countries. In the future, China's vaccine companies will continue to promote technology transfer to developing countries and support companies in 
carrying out international production ventures. Over the past year or so, the raging COVID-19 pandemic has shown us that mankind's honour and disgrace are shared, and our destinies are connected. As the safety, effectiveness, and convenience of China's vaccines have been fully proven, China will persist in thinking about the needs of developing countries and take concrete actions to promote a fair and reasonable distribution of global vaccines.

\section{Conclusions}

COVID-19 not only threatens human health but also has a major adverse effect on social and economic development. In fighting the pandemic and protecting the lives of citizens, medical workers, biomedical experts, and relevant pandemic prevention units have paid a heavy price. ${ }^{22-24}$ In this research, we explored China's vaccination strategies and challenges. Accordingly, we identified the causes of the high vaccination rate in China, including technical and nontechnical factors. Considering the impact of China's high vaccination rate on the global pandemic, we argue that it has strengthened China's opportunities and capabilities to participate in global development, enhanced the equity of vaccines and offered the global community more choices.

At present, COVID-19 has spread to more than 100 countries and regions. Many countries failed to achieve effective prevention and control in the early stage of the pandemic, leading to the rapid spread of the disease. In facing the variants of COVID-19, it is important to speed up vaccination to save lives and to enable the economy to recover.

\section{Abbreviations}

COVID-19, Coronavirus disease 2019; COVAX, COVID19 Vaccines Global Access.

\section{Acknowledgments}

This research was funded by National Social Science Found of Colleges and Universities Ideological and Political Education Courses Research Project (20VSZ013).

\section{Disclosure}

The authors report no conflicts of interest in this work.

\section{References}

1. Mathieu E, Ritchie H, Ortiz-Ospina E, et al. A global database of COVID-19 vaccinations. Nat Hum Behav. 2021;5:947-953.

2. Xing C, Zhang R. COVID-19 in China: responses, challenges and implications for the health system. Healthcare. 2021;9(1):82. doi: $10.3390 /$ healthcare 9010082
3. Zhang J, Zhang R. COVID-19 in China: power, transparency and governance in public health crisis. Healthcare. 2020;8(3):288. doi: $10.3390 /$ healthcare 8030288

4. Yuan B, Jian W, He L, Wang B, Balabanova D. The role of health system governance in strengthening the rural health insurance system in China. Int J Equity Health. 2017;16(1):44. doi:10.1186/s12939017-0542-x

5. Burki T. China's successful control of COVID-19. Lancet Infect Dis. 2020;20(11):1240-1241. doi:10.1016/S1473-3099(20)30800-8

6. National Health Commission. China has fully vaccinated 1 billion people; 2021. Available from: http://www.nhc.gov.cn/xcs/yqfkdt/ 202109/bf2cf785ce0544ae818a76ffbb18ca79.shtml.Accessed November 8, 2021.

7. Jason Fang J. China threatens public spaces ban on people who have not had a COVID-19 vaccination'; 2021. Available from: https:// www.abc.net.au/news/2021-07-16/china-threaten-bans-unvaccinatedfrom-public-spaces-some-cities/100296584. Accessed November 8, 2021.

8. Kupferschmidt K, Cohen J. Can China's COVID-19 strategy work elsewhere? Science. 2020;367(6482):1061-1062. doi:10.1126/ science.367.6482.1061

9. Pan X-B. Application of personal-oriented digital technology in preventing transmission of COVID-19, China. Irish J Med Sci. 2020;189 (4):1145-1146. doi:10.1007/s11845-020-02215-5

10. Duan Y, Shi J, Wang Z, Zhou S, Jin Y, Zheng Z-J. Disparities in COVID-19 vaccination among low-, middle-, and high-income countries: the mediating role of vaccination policy. Vaccines. 2021;9 (8):905. doi:10.3390/vaccines9080905

11. Kapoor A, Guha S, Kanti Das M, Goswami KC, Yadav R. Digital healthcare: the only solution for better healthcare during COVID-19 pandemic? Indian Heart J. 2020;72(2):61-64. doi:10.1016/j. ihj.2020.04.001

12. Fayed AA, Al Shahrani AS, Almanea LT, et al. Willingness to receive the COVID-19 and seasonal influenza vaccines among the Saudi population and vaccine uptake during the initial stage of the national vaccination campaign: a cross-sectional survey. Vaccines. 2021;9 (7):765. doi:10.3390/vaccines 9070765

13. Götz G, Herold D, Klotz P-A, Schäfer JT. Efficiency in COVID-19 vaccination campaigns - a comparison across Germany's federal states. Vaccines. 2021;9(7):788. doi:10.3390/vaccines9070788

14. Herrera-Peco I, Jiménez-Gómez B, Romero Magdalena CS, et al. Antivaccine movement and COVID-19 negationism: a content analysis of Spanish-written messages on twitter. Vaccines. 2021;9 (6):656. doi:10.3390/vaccines9060656

15. King I, Heidler P, Marzo RR. The long and winding road: uptake, acceptability, and potential influencing factors of COVID-19 vaccination in Austria. Vaccines. 2021;9(7):790. doi:10.3390/ vaccines 9070790

16. Zhao J, Hu Y. China to become biggest global provider of COVID-19 vaccines: expert; 2021. Available from: https://www.globaltimes.cn/ page/202108/1231387.shtml. Accessed November 8, 2021.

17. Kukreti S, Lu M-Y, Lin Y-H, et al. Willingness of Taiwan's healthcare workers and outpatients to vaccinate against COVID-19 during a period without community outbreaks. Vaccines. 2021;9(3):246. doi: $10.3390 /$ vaccines 9030246

18. Savoia E, Piltch-Loeb R, Goldberg B, et al. Predictors of COVID-19 vaccine hesitancy: socio-demographics, co-morbidity, and past experience of racial discrimination. Vaccines. 2021;9(7):767. doi: $10.3390 /$ vaccines 9070767

19. Hopman J, Allegranzi B, Mehtar S. Managing COVID-19 in lowand middle-income countries. JAMA. 2020;323(16):1549. doi:10.1001/jama.2020.4169

20. Shekhar R, Sheikh AB, Upadhyay S, et al. COVID-19 vaccine acceptance among health care workers in the United States. Vaccines. 2021;9(2):119. doi:10.3390/vaccines9020119 
21. Cheng Y, Yu J, Shen Y, Huang B. Coproducing responses to COVID -19 with community-based organizations: lessons from Zhejiang Province, China. Public Adm Rev. 2020;80(5):866-873. doi:10.1111/puar.13244

22. Sun Z, Cheng X, Zhang R, Yang B. Factors influencing rumour re-spreading in a public health crisis by the middle-aged and elderly populations. Int J Environ Res Public Health. 2020;17(18):6542. doi:10.3390/ijerph17186542
23. Sun Z, Yang B, Zhang R, Cheng X. Influencing factors of understanding COVID-19 risks and coping behaviors among the elderly population. Int J Environ Res Public Health. 2020;17(16):5889. doi:10.3390/ijerph17165889

24. Wang J, Zhang R. COVID-19 in Rural China: features, challenges and implications for the healthcare system. J Multidiscip Healthc. 2021;14:1045-1051. doi:10.2147/JMDH.S307232

\section{Publish your work in this journal}

Risk Management and Healthcare Policy is an international, peerreviewed, open access journal focusing on all aspects of public health, policy, and preventative measures to promote good health and improve morbidity and mortality in the population. The journal welcomes submitted papers covering original research, basic science, clinical \& epidemiological studies, reviews and evaluations, guidelines, expert opinion and commentary, case reports and extended reports. The manuscript management system is completely online and includes a very quick and fair peer-review system, which is all easy to use. Visit http://www.dovepress.com/testimonials.php to read real quotes from published authors.

Submit your manuscript here: https://www.dovepress.com/risk-management-and-healthcare-policy-journal 